\title{
ELECTROCHEMICAL FACETING AND PREFERRED CRYSTALLOGRAPHIC ORIENTATION OF RHODIUM ELECTRODES
}

\author{
E. CUSTIDIANO, S. PIOVANO and A.J. ARVIA \\ Instituto de Investigaciones Fisicoquimicas Teóricas y Aplicadas (INIFTA) ${ }^{\star}$, C.C. 16, Sucursal 4, \\ (1900) La Plata (Argentina)
}

A.C. Chialvo

Programa de Electroquimica Aplicada e Ingeniería Electroquimica (PRELINE), Santiago des Estero 2829, (3000) Santa Fe (Argentina)

\section{IPOHORSKI}

Departamento de Materiales, Comisión Nacional de Energía Atómica, Buenos Aires (Argentina)

(Received 4th July 1986; in revised form 25th November 1986)

\begin{abstract}
The electrochemical faceting of $\mathrm{Rh}$ in $1 \mathrm{M} \mathrm{H}_{2} \mathrm{SO}_{4}$ can be developed by applying repetitive periodic potentials in the range -0.1 to $1.2 \mathrm{~V}$ (vs. RHE) at frequencies greater than $0.5 \mathrm{kHz}$. The degree of electrochemical faceting, as followed voltammetrically at $0.1 \mathrm{~V} / \mathrm{s}$ in the $\mathrm{H}$-adatom potential range, exhihits two different situations, depending on the lower and upper limits of the periodic potential. In one case, the voltammogram exhibits two sharp reversible conjugated peaks related to the H-adatom reactions, similar in shape to those reported for Rh (111), although the peak potentials are closer to those found for $\mathrm{Rh}(110)$. In the other case, a complex voltammogram is obtained which can be related to a predominance of (111) and (100) crystallographic faces. SEM micrographs confirm the development of electrochemical faceting involving steps, terraces and pyramidal structures which are related to the preferred orientations.
\end{abstract}

\section{INTRODUCTION}

It was recently shown that the electrochemical faceting of polycrystalline (pc) $\mathbf{P t}$ in acid can develop different preferred crystallographic orientations, such as the (100), (110) or (111) orientation, according to the preset characteristics of the fast periodic potential programme applied to the electrode [1-3]. Preferred oriented electrochemical faceting has been produced for Pt electrodes, either pc or single

\footnotetext{
‡ Facultad de Ciencias Exactas, Universidad Nacional de La Plata.
} 
crystal [3], and pc Au electrodes [4]. The resulting surfaces exhibit very clear geometric details when observed by scanning electron microscopy $[5,6]$ and scanning electron tunnelling microscopy [7]. The development of electrochemical faceting can be followed through conventional low sweep rate voltammetry run in the potential range of the $\mathrm{H}$-adatom reactions for $\mathrm{Pt}$ and in the potential range of lead upd for Au [8].

The present work was undertaken to investigate the electrochemical faceting of $\mathrm{pc} R \mathrm{Rh}$ in acid solutions. The amount of research work on these electrodes is comparatively much less extensive than that on Pt electrodes. As for the latter, it is possible, in principle, to follow also voltammetrically the development of electrochemical faceting on $\mathrm{Rh}$ in acid solutions through the $\mathrm{H}$-adatom reactions. In this respect, results published in recent years $[9,10]$ on the voltammetric behaviour of single-crystal Rh electrodes appear particularly attractive for the sake of comparison although it should be considered that these results imply an electrochemical cleaning applied to pc as well as to single-crystal rhodium electrodes which probably led to unknown surface perturbations.

\section{EXPERIMENTAL}

The starting material for the preparation of the working electrodes was $0.5 \mathrm{~mm}$ diameter pc Rh wire (Johnson Matthey Chem. Co.). The electrochemical faceting was done on two types of electrodes: (i) $\mathrm{pc} R \mathrm{Rh}$ wire electrodes which had been previously polished with fine grain alumina and immersed in a $\mathrm{HNO}_{3}+\mathrm{H}_{2} \mathrm{SO}_{4}$ mixture without any thermal pretreatment; and (ii) bead-shaped polyoriented (po) $\mathrm{Rh}$ electrodes made by melting the extreme of a $\mathbf{R h}$ wire in an oxygen-air torch flame and cooling down in air. The geometric area of the po electrodes was of the order of $0.1 \mathrm{~cm}^{2}$. A complete electrochemical run consisted of the three following stages: (i) electrochemical faceting; (ii) conventional voltammetry at $0.1 \mathrm{~V} / \mathrm{s}$ to follow the changes caused by the electrochemical faceting; and (iii) SEM observations and micrography.

The electrochemical faceting of either pc or po $\mathrm{Rh}$ was performed in $1 \mathrm{M} \mathrm{H}_{2} \mathrm{SO}_{4}$ at $25^{\circ} \mathrm{C}$ using a low-resistance electrochemical cell which included a working electrode surrounded by a $\mathrm{Rh}$ counter-electrode and a RHE as reference. The cell design was similar to that described for the electrochemical faceting of $\mathrm{Pt}$ to satisfy a reasonable homogeneous current [1,2]. Either repetitive triangular potential sweeps (RTPS) or repetitive square wave potential signals (RSWPS) were applied to the working electrode during a preset time $(t)$. For the RTPS treatment, the upper $\left(E_{\mathrm{s}, \mathrm{u}}\right)$ and lower $\left(E_{\mathrm{s}, 1}\right)$ switching potentials and frequencies $(f)$ covered the following ranges: $0.7 \mathrm{~V}<E_{\mathrm{s}, \mathrm{u}}<1.2 \mathrm{~V},-0.1 \mathrm{~V}<E_{\mathrm{s}, 1}<0.3 \mathrm{~V}$ and $0.26 \mathrm{kHz}<f<4 \mathrm{kHz}$. Analogously, for RSWPS, a relatively wide range of upper $\left(E_{\mathrm{u}}\right)$ and lower $\left(E_{1}\right)$ potential steps and frequencies were used, namely, $0.7 \mathrm{~V}<E_{\mathrm{u}}<1.4 \mathrm{~V},-0.1$ $\mathrm{V}<E_{1}<0.35 \mathrm{~V}$ and $0.3 \mathrm{kHz}<f<7 \mathrm{kHz}$. In both cases, the potential ranges of the fast periodic perturbation were within the potential range of thermodynamic stability of bulk water. 
The extent of electrochemical faceting was followed voltammetrically at $0.1 \mathrm{~V} / \mathrm{s}$, in $1 \mathrm{M} \mathrm{H}_{2} \mathrm{SO}_{4}$, by covering the potential range of $\mathrm{H}$-adatoms, and eventually the initial stage of the oxide layer electroformation and electroreduction. For this purpose, the voltammogram of untreated pc Rh electrode was taken for comparison.

Finally, SEM micrograph of electrofaceted $\mathrm{Rh}$ surfaces were obtained in a conventional way to correlate with electrochemical data.

\section{RESULTS}

A conventional voltammogram of pc $\mathrm{Rh}$ in $1 \mathrm{M} \mathrm{H}_{2} \mathrm{SO}_{4}$ run at $0.1 \mathrm{~V} / \mathrm{s}$ between 0.03 and $1.20 \mathrm{~V}$ exhibits, in agreement with previously reported data [11], the $\mathrm{H}$-electroadsorption/electrodesorption current peaks in the $0-0.25 \mathrm{~V}$ range (Fig. 1). Oxygen electroadsorption starts at $0.5 \mathrm{~V}$ and O-electrodesorption, eventually including some oxide electroreduction, occurs from $1.1 \mathrm{~V}$ downwards. In Fig. 1, only the $\mathrm{H}$-adatom peaks are depicted because the changes in this part of the voltammogram are used to follow the degree of electrochemical faceting of $R h$.

The voltammetric response of electrochemically faceted (ef) $\mathrm{Rh}$ in $1 \mathrm{M} \mathrm{H}_{2} \mathrm{SO}_{4}$ at $0.1 \mathrm{~V} / \mathrm{s}$ in the $\mathrm{H}$-adatom potential range depends on the characteristics of the previous fast periodic potential programme applied to the electrode and its duration. The corresponding stabilized voltammogram is obtained in only a few cycles at $0.1 \mathrm{~V} / \mathrm{s}$.

In principle, $\mathrm{Rh}$ presents two distinguishable types of voltammetric response. The first type is found for $E_{\mathrm{s}, \mathrm{u}}=0.90 \mathrm{~V}, E_{\mathrm{s}, \mathrm{l}}=0.10 \mathrm{~V}, f=1.0 \mathrm{kHz}$ and $t=15 \mathrm{~min}$ under RTPS (Fig. 2a) and $E_{\mathrm{u}}=0.95 \mathrm{~V}, E_{1}=0.13 \mathrm{~V}, f=3.7 \mathrm{kHz}$ and $t=30$ min under RSWPS (Fig. 2b). The corresponding voltammograms exhibit extremely sharp single anodic and cathodic symmetric $\mathrm{H}$-adatom peaks, the peak potential difference at 0.1 $\mathrm{V} / \mathrm{s}$ being equal to $0.025 \mathrm{~V}$. In these cases, the reversible current contributions appearing for pc Rh (Fig. 1) as complementary humps on the positive potential side of the main $\mathrm{H}$-adatom peaks are no longer observed. The voltammograms for ef $\mathrm{Rh}$ show only a slight increase in voltammetric charge as compared to the blank and are

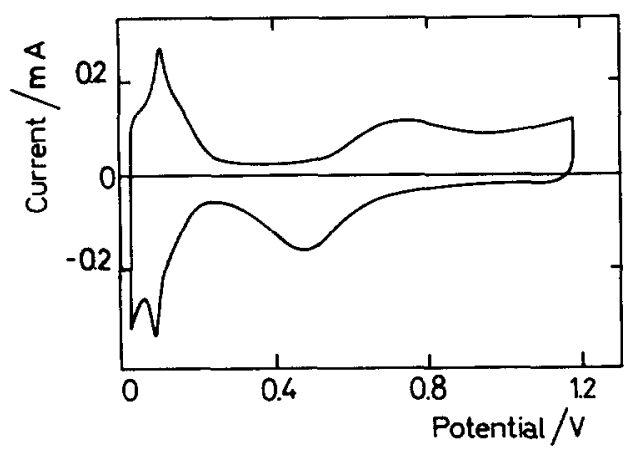

Fig. 1. Voltammogram of pc Rh (wire) in $1 \mathrm{M} \mathrm{H}_{2} \mathrm{SO}_{4}$ (blank). $v=0.1 \mathrm{~V} / \mathrm{s}, 30^{\circ} \mathrm{C}$. 


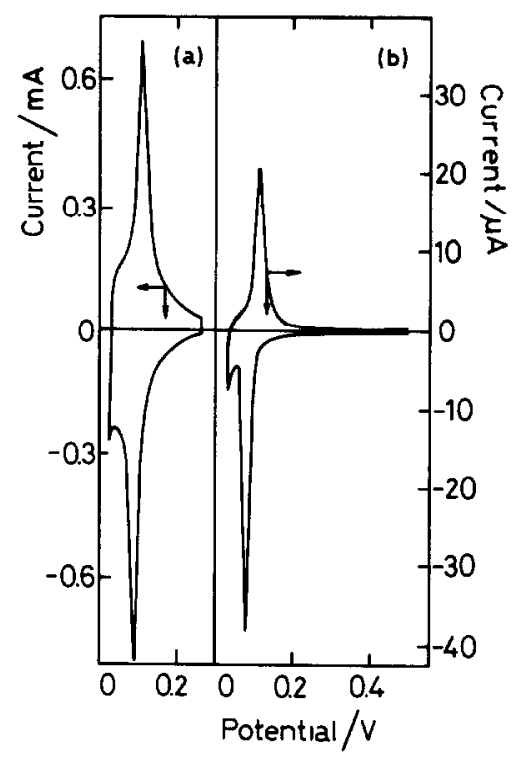

Fig. 2. Voltammograms of $\mathrm{Rh}$ in $1 \mathrm{M} \mathrm{H}_{2} \mathrm{SO}_{4}$ after electrochemical faceting, $30^{\circ} \mathrm{C}$. (a) Electrochemical faceting developed through application of RTPS to a pc wire $R h$ electrode of geometric area $1.5 \mathrm{~cm}^{2}$. $E_{\mathrm{s}, 1}=0.10 \mathrm{~V}, E_{\mathrm{s}, \mathrm{u}}=0.90 \mathrm{~V}, f=1 \mathrm{kHz}, t=15 \mathrm{~min}$. (b) Electrochemical faceting developed through application of symmetric RSWPS to a po bead electrode of geometric area $0.1 \mathrm{~cm}^{2} . E_{1}=0.13 \mathrm{~V}$, $E_{\mathrm{u}}=0.95 \mathrm{~V}, f=3.7 \mathrm{kHz}, t=30 \mathrm{~min}$.

very stable to RTPS at $0.1 \mathrm{~V} / \mathrm{s}$ between 0.02 and $0.26 \mathrm{~V}$ or when $E_{\mathrm{s}, \mathrm{u}}$ is extended up to $1.2 \mathrm{~V}$. However, when $E_{\mathrm{s}, \mathrm{u}}$ is set at potentials greater than $1.0 \mathrm{~V}$ some oxide formation already takes place. The oxide electroreduction current presumably overlaps to some extent the $\mathrm{H}$-adatom electroadsorption peak from $0.2 \mathrm{~V}$ downwards. This probably causes the slight increase in the voltammetric charge. Furthermore, for ef $\mathrm{Rh}$ the potentials of the anodic and cathodic peaks related to O-electrosorption are slightly more positive than those for pc Rh. Nevertheless, prolonged cycling between 0.1 and $1.2 \mathrm{~V}$ at $0.1 \mathrm{~V} / \mathrm{s}$ progressively restores the voltammogram to that of $\mathrm{pc} \mathrm{Rh}$. The optimal conditions for developing the first type of voltammetric response of ef $R h$ are given in Fig. 2 for both the RTPS and RSWPS procedure.

The SEM micrographs of the first type of bead-shaped ef Rh electrodes containing only a few crystallographic grains reveal different symmetric regions on the surface (Fig. 3a) presumably surrounding crystallographic poles (Fig. 3b), resembling a step and terrace structure along zones between the low-index corners of the triangular region of the stereographic projection. The centre of the square area (Fig. 3a) contains a large number of square-base pyramids approaching a radial alignment with an average size increasing from the centre outwards (Figs. $3 \mathrm{~b}$ and $3 \mathrm{c}$ ). At the border of the geometric figure depicted in Fig. 3a, a sharp transition in the 

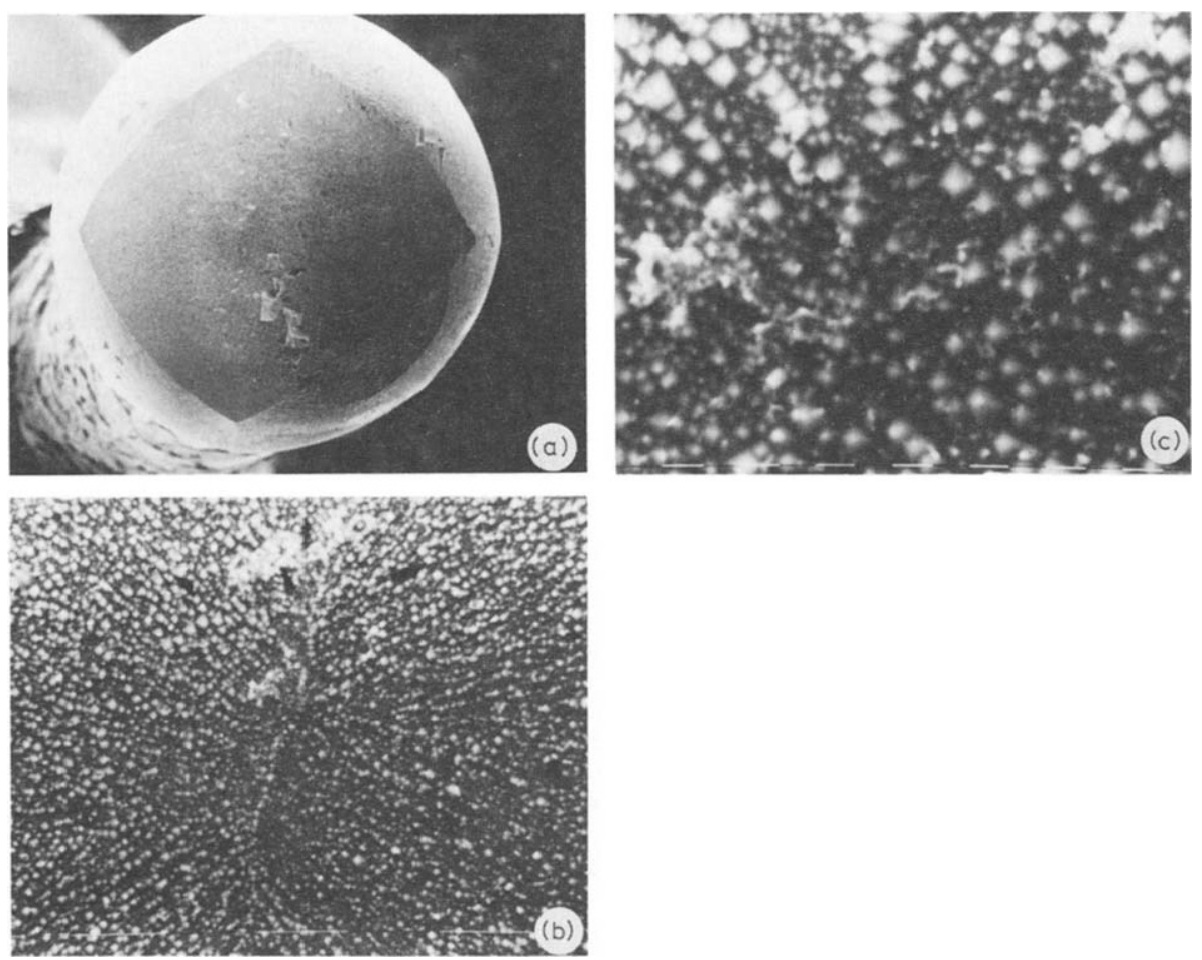

Fig. 3. SEM micrographs. (a) Bead-shaped ef Rh electrode ( $\times 60)$ The corresponding voltammogram is depicted in Fig. 2b. (b,c) Detailed surface structures $(\times 1000$ and $\times 4000$, respectively) of the central portion of the dark square area shown in (a).

faceted structure to large parallel steps and irregular border terraces are observed (Figs. 4a-4d). Flat areas as large as $100 \mu \mathrm{m}^{2}$ can be distinguished.

The SEM micrographs of ef $\mathrm{Rh}$ wire electrodes become more cumbersome because of the number of crystallographic grains and grain boundaries (Fig. 5). Grains behave as preferred single crystals with the same preferred orientations but are distributed differently in space. The micrographs also reveal randomly distributed crystallographic pits as well as electrodeposition of metal under a well-defined geometry.

The second type of voltammetric response for ef $\mathrm{Rh}$ in $1 \mathrm{M} \mathrm{H}_{2} \mathrm{SO}_{4}$ can be obtained either through RTPS or RSWPS by using an upper potential limit, either $E_{\mathrm{s}, \mathrm{u}}$ or $E_{\mathrm{u}}$, respectively, greater than those reported above for the first type. For an electrode which was electrofaceted through RSWPS for $E_{1}=0.25 \mathrm{~V}, E_{\mathrm{u}}=1.10 \mathrm{~V}$, $f=5 \mathrm{kHz}$ and $t=5 \mathrm{~min}$, the stabilized voltammogram at $0.02 \mathrm{~V} / \mathrm{s}$ in the H-adatom potential range and that resulting at $0.05 \mathrm{~V} / \mathrm{s}$ by covering the $\mathrm{O}$ - and $\mathrm{H}$-adatom potential ranges are depicted in Figs. $6 a$ and $6 b$, respectively. The stabilized voltammogram consists of complex anodic and cathodic peaks implying that the 

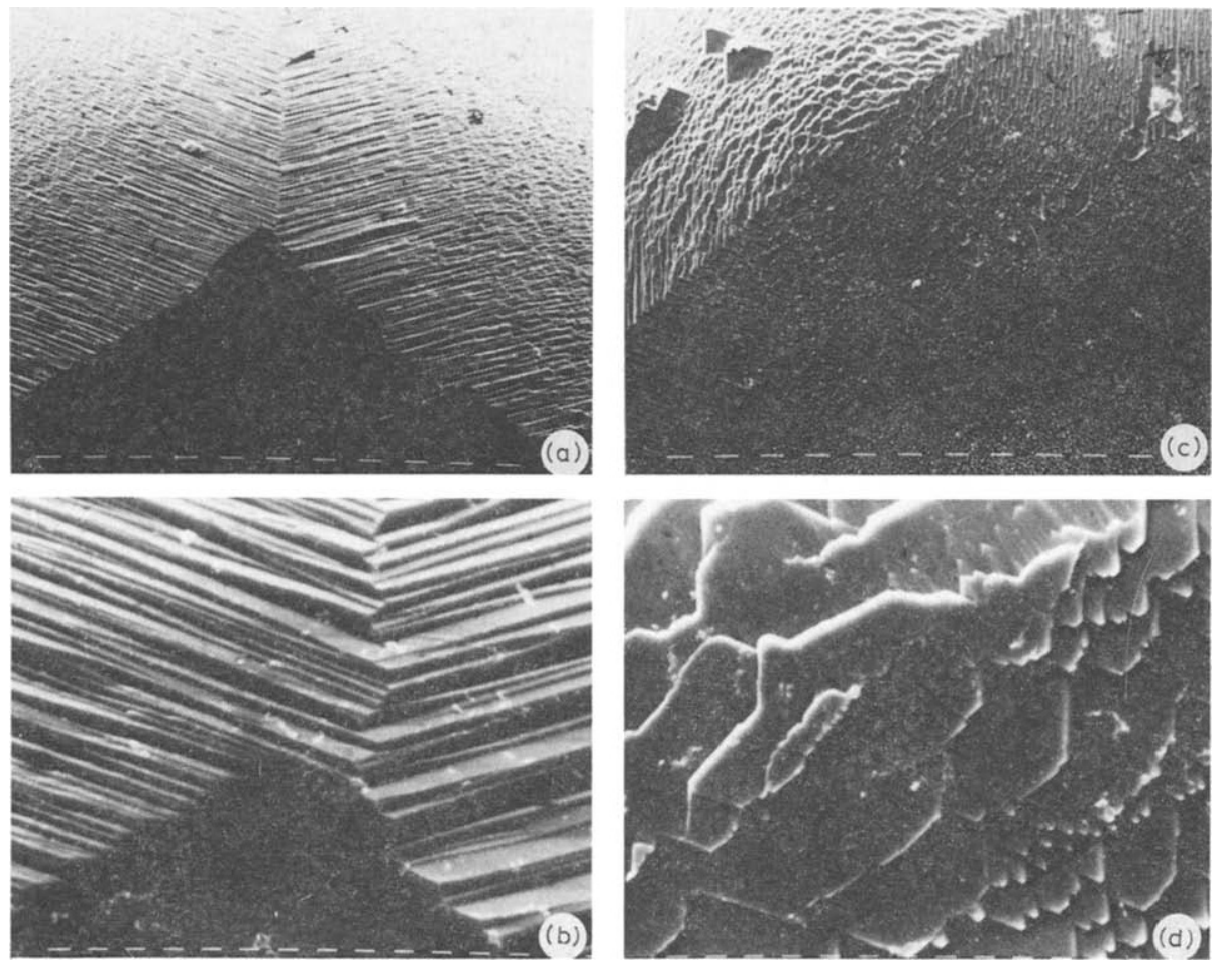

Fig. 4. SEM micrographs corresponding to details at the boundary regions between the dark and clear areas depicted in Fig. 3a. (a,b) Corner regions ( $\times 250$ and $\times 2000$, respectively); (c,d) side regions $(\times 250$ and $\times 2000$, respectively).
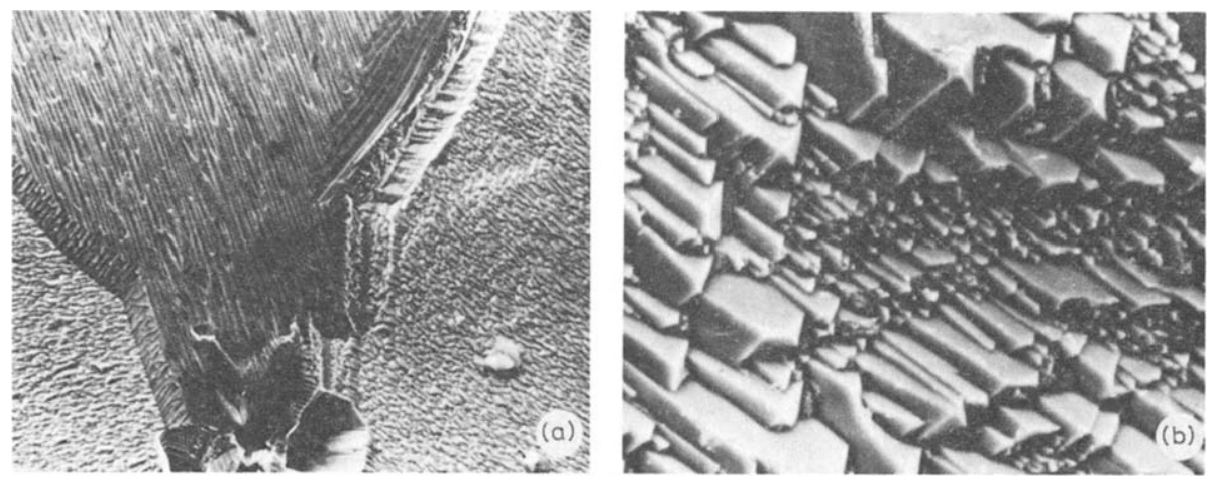

Fig. 5. SEM micrographs of an ef $\mathrm{Rh}$ wire electrode. The corresponding voltammogram is depicted in Fig. 2b. (a) Typical grain and grain boundaries $(\times 500)$; (b) detailed grain structure $(\times 2000)$. 


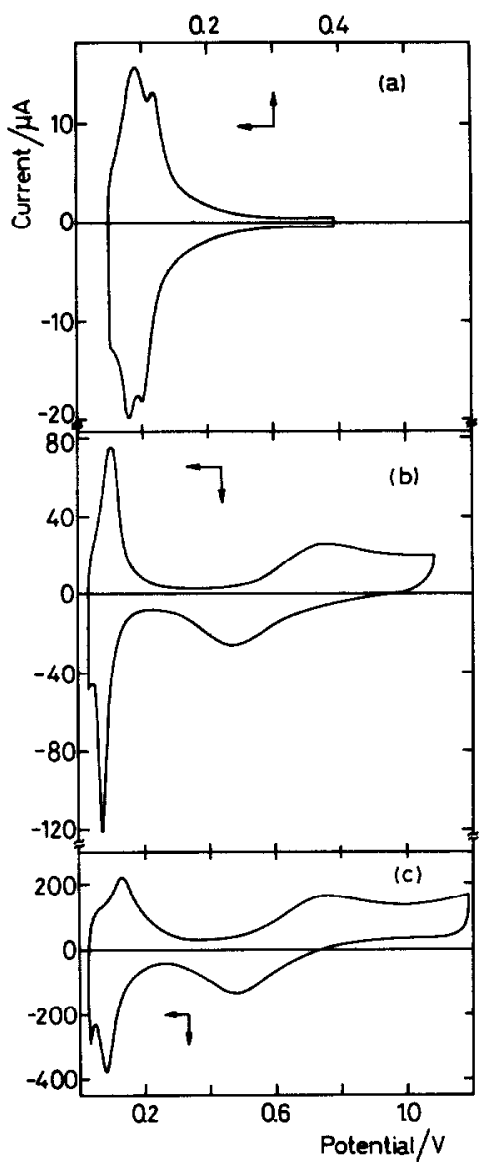

Fig. 6. Voltammograms of $\mathrm{Rh}$ in $1 \mathrm{M} \mathrm{H}_{2} \mathrm{SO}_{4}$ after electrochemical faceting, $30^{\circ} \mathrm{C}$, through RSWPS. $E_{1}=0.25 \mathrm{~V}, E_{\mathrm{u}}=1.10 \mathrm{~V}, f=5 \mathrm{kHz}, t=5 \mathrm{~min}$. (a) Stabilized voltammogram resulting at $0.02 \mathrm{~V} / \mathrm{s}$ in the $\mathrm{H}$-adatom potential range; (b) stabilized voltammogram resulting at $0.05 \mathrm{~V} / \mathrm{s}$ by covering the $\mathrm{O}$ - and $\mathrm{H}$-adatom potential ranges; (c) voltammogram at $0.1 \mathrm{~V} / \mathrm{s}$ resulting after electrochemical faceting through RSWPS; $E_{1}=0.25 \mathrm{~V}, E_{\mathrm{u}}=1.20 \mathrm{~V}, f=0.5 \mathrm{kHz}, t=30 \mathrm{~min}$.

H-adatom charges are distributed in a potential range wider than those in the voltammogram depicted in Fig. 2 . On the assumption that the complex voltammetric peaks involve the overlapping of only two peaks, the corresponding peak potential values can be only roughly estimated. The potentials of the $\mathrm{H}$-adatom conjugated peaks located at lower potentials are close to those for the single pair of conjugated peaks shown in Fig. 2a.

When the RSWPS characteristics are modified in the direction that $f$ is decreased and $E_{\mathrm{u}}$ is increased, the electrochemical faceting as followed through voltammetry is less noticeable and is accompanied by an increase in voltammetric 

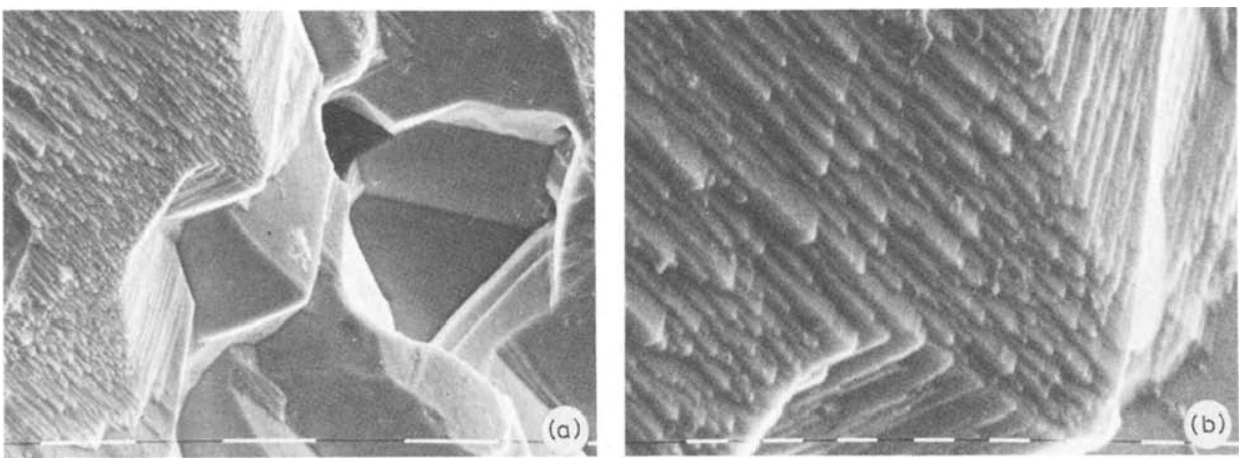

Fig. 7. SEM micrographs of an ef Rh electrode. The corresponding voltammogram is depicted in Fig. 6 . (a) $\times 1600$; (b) $\times 6400$.

area (Fig. 6c). In this case, the electroreduction voltammogram involves a cathodic background current extending from ca. $0.4 \mathrm{~V}$ downwards. This behaviour corresponds to that of a $\mathrm{Rh}$ electrode which has accumulated an oxide layer during the fast RSWPS cycling [12] under the conditions indicated in Fig. 6c.

The SEM micrographs (Fig. 7) of the second type of ef Rh electrode surfaces exhibit a clear faceting with a characteristic development of step and terraces in different regions.

\section{DISCUSSION}

The electrochemical faceting of pc $\mathrm{Rh}$ in $1 \mathrm{M} \mathrm{H}_{2} \mathrm{SO}_{4}$ develops in a manner similar to that more extensively studied for $\mathrm{Pt}$ [1-5]. SEM micrographs and conventional voltammetry reveal that for $\mathrm{Rh}$, as for other noble metals, electrochemical faceting implies a preferred crystallographic mono-orientation. The possibility of identifying the predominant type of crystallographic orientation can be attempted through a direct comparison of the voltammograms recorded for ef $\mathrm{Rh}$ electrodes with those reported in the literature [8-10] for different single-crystal $\mathbf{R h}$ electrodes. It was demonstrated that the electroadsorption-electrodesorption spectrum for $\mathrm{H}$-adatoms, for a constant ionic composition of the solution, depends basically on the crystallographic orientation of the substrate. In this respect, the voltammetric response of noble metal electrodes in $\mathrm{H}_{2} \mathrm{SO}_{4}$ solutions brings about sharp peaks which are probably associated with a concerted interaction among sites of a particular crystallographic plane, $\mathrm{H}$-adatoms, ions and solvent molecules at the electrochemical interface [13]. On the other hand, it has already been established that the difference in surface structure of $\mathrm{Rh}$ changes the photoelectric work function and is reflected through the adsorption behaviour of hydrogen and oxygen from the gas phase [14], as should be expected in a more general way regarding the existence of different adsorbed forms of hydrogen according to the state and crystallographic structure of the metal surface [15-18]. 
Rh single-crystal faces present a single adsorption-desorption pair of peaks for $\mathrm{H}$-adatoms, the voltammetric profiles depending on the crystallographic orientation of the face. From a direct comparison of results published recently [8-10] on $\mathrm{H}$-electroadsorption on single-crystal $\mathrm{Rh}$ electrodes with those depicted in Fig. 2, it can be seen that the voltammograms of the ef $R h$ electrode, as far as the shape is concerned, approaches that reported for the Rh (111) face. However, the location of peak potentials appears closer to that given for the $R h(110)$ face. At present, this ambiguity cannot be solved either voltammetrically or through SEM micrographs (Fig. 3a), which are rather different from the low-index faceting patterns expected for po fcc single-crystal spheres [3]. Nevertheless, it should be noted that the data currently available on $R h$ single crystals due to the electrochemical treatment applied to these electrodes [10] are not sufficiently reliable to derive in this case a definite conclusion about the development of predominantly (111) face orientation during the electrochemical faceting of pc Rh, except to say that low-index crystallographic faces, probably either (111) or less likely (110) preferred orientation, are accomplished after the fast periodic potential treatment.

On the other hand, the voltammograms depicted in Fig. 6a can be reasonably interpreted as the sum of two predominant contributions corresponding to the (111) and $(100)$ faces, respectively. For the $R h(100)$ face, the peak potentials of the $\mathrm{H}$-adatom electro adsorption-electrodesorption remain practically unchanged on running the potential sweeps up to $1.2 \mathrm{~V}$, and these are slightly more positive and the corresponding voltammetric charges extend over a potential range greater than that for the (111) face. Likewise, the reversibility of the H-adatom reaction on the (100) face is qualitatively higher than that on the (111) face. These data explain, in principle, why the complex voltammetric profiles depicted in Fig. 6a behave as reasonable reversible electrochemical systems although further conclusions about the degree of reversibility of the reactions corresponding to the different peaks are obscured because in this case the electroreduction voltammogram is accompanied by a surface oxide electroreduction which in turn causes an additional change in the electrode roughness (Fig. 6c). This situation can be related to the hydrous oxide layer formed when the $E_{u}$ value in the RSWPS is extended to about $1.5 \mathrm{~V}[12,19]$.

SEM micrographs show that the development of electrofaceting implies regions undergoing localized electrocrystallization and crystallographic localized attack. These processes occur in a selective way as one would expect from the theory of electrochemical faceting recently advanced for $\mathrm{Pt}[20,21]$. Accordingly, the faradaic processes associated with electrofaceting are determined mainly by the potential of zero charge, water hydrophilicity and the anion-metal interaction for each crystallographic face [4]. Unfortunately, for the case of $\mathrm{Rh}$ as well as for Pt no data are available to advance the understanding of the process in this direction.

In conclusion, the development of the electrochemical faceting of Rh appears as a surface reforming process where the contributions of low-index (110), (111) and (100) faces appear to be the most important. In this respect, as the steps formed by the low-index faces are relatively large in comparison with the atomic scale, the influence of high-index faces cannot be observed through conventional voltamme- 
try. The reproducibility and stability of the electrofaceted surface to electroadsorption-electrodesorption cycles in the $\mathrm{H}$-, $\mathrm{OH}$ - and $\mathrm{O}$-adatom regions are sufficiently satisfactory to encourage the use of ef $\mathrm{Rh}$ electrodes for a more rational approach to the study of electrocatalytic reactions instead of $\mathrm{pc} R \mathrm{R}$ electrodes usually subjected to arbitrary and uncontrolled surface pretreatments.

\section{ACKNOWLEDGEMENTS}

This research project was financially supported by the Universidad Nacional de La Plata, the Consejo Nacional de Investigaciones Científicas y Técnicas and the Comisión de Investigaciones Científicas de la Provincia de Buenos Aires.

\section{REFERENCES}

1 R.M. Cerviño, W.E. Triaca and A.J. Arvia, J. Electroanal. Chem., 182 (1985) 51.

2 J.C. Canullo, W.E. Triaca and A.J. Arvia, J. Electroanal. Chem., 175 (1984) 337.

3 J.C. Canullo, W.F. Triaca and A.J. Arvia, J. Electroanal. Chem., 200 (1986) 397.

4 C.L. Perdriel, M. Ipohorski and A.J. Arvia, J. Electroanal. Chem., 215 (1986) 317.

5 R.M. Cerviño, A.J. Arvia and W. Vielstich, Surf. Sci., 154 (1985) 623.

6 W.E. Triaca, T. Kessler, J.C. Canullo and A.J. Arvia, J. Electrochem. Soc., in press.

7 J. Gómez, L. Vázquez, A.M. Baró, N. García, C.L. Perdriel, W.E. Triaca and A.J. Arvia, Nature (London), 323 (1986) 612.

8 A. Hamelin and J. Lipkowski, J. Electroanal. Chem., 171 (1984) 317.

9 A.M. Meretskii, I.V. Kudryashov and Yu.B. Vasiliev, Sov. Electrochem., 13 (1977) 447.

10 A.S. Lapa, V.A. Safonov, O.A. Petrii and N.L. Korenovskii, Sov. Electrochem., 20 (1984) 1439.

11 C. Pallotta, N.R. de Tacconi and A.J. Arvia, Electrochim. Acta, 26 (1981) 261.

12 A.C. Chialvo, W.E. Triaca and A.J. Arvia, J. Electroanal. Chem., submitted.

13 S.A. Bilmes, M.C. Giordano and A.J. Arvia, J. Electroanal. Chem., in press.

14 S.I. Sergeev, M.E. Belyaeva. N.A. Shurmovskaya, G.M. Kornacheva and T.V. Kalish, Sov. Electrochem., 16 (1980) 175

15 K.E. Lu and R.R. Rye, Surf. Sci., 45 (1974) 677.

16 K. Christmann, G. Ertl and T. Pignet, Surf. Sci., 54 (1976) 365.

17 A.A. Yakovleva, I.L. Kubinova, A.M. Kleshchevnikov, E.N. Lubnin and Ya.M. Kolotyrkin, Sov. Electrochem., 20 (1984) 374.

18 T.L. Barr, J. Phys. Chem., 32 (1978) 1801.

19 C.L. Perdriel, W.E. Triaca and A.J. Arvia, J. Electroanal. Chem., 205 (1986) 279.

20 A.J. Arvia, J.C. Canullo, E. Custidiano, C.L. Perdriel and W.E. Triaca, Electrochim. Acta, 31 (1986) 1359. 